\title{
Sparsely Granulated Non-Functioning Corticotroph Adenoma
}

National Cancer Institute

\section{Source}

National Cancer Institute. Sparsely Granulated Non-Functioning Corticotroph Adenoma.

NCl Thesaurus. Code C154432.

A sparsely granulated corticotroph adenoma not associated with a hormonal syndrome. 